\title{
TRADIÇÃO X INOVAÇÃO: patrimônio cultural e memória através dos repertórios musicais do carnaval Zé Pereira em Florianópolis/SC
}

\author{
Lisandra Barbosa Macedo*
}

\section{Resumo}

O presente artigo procura identificar as articulações e os movimentos de preservação da identidade cultural na Ilha de Santa Catarina, que ocorrem, implicitamente, na revitalização de eventos como o Carnaval Zé Pereira. Este evento acontece há mais de cem anos nas imediações do bairro Ribeirão da Ilha, em Florianópolis/SC e, nos últimos anos, tem sido destaque na programação dos eventos carnavalescos no estado, tanto na mídia, quanto pelo aumento no número de participantes. A escolha do repertório musical por parte dos dirigentes da Sociedade Musical e Recreativa Lapa, que promove o evento, e as manifestações das comunidades envolvidas e da mídia, com relação aos ritmos executados, geram discussões que podem enriquecer muito as questões envolvidas na preservação das manifestações culturais na localidade tombada pelo patrimônio histórico local.

Palavras-chave: Patrimônio Imaterial. História. Memória Musical.

Localizado no sul da Ilha de Santa Catarina, o conjunto histórico do Ribeirão da Ilha, tombado como Patrimônio Cultural Material do município, surgiu por volta de 1760, com a vinda, sobretudo, de imigrantes açorianos. Sendo assim, constitui-se arquitetonicamente por casas e igrejas em estilo luso-açoriano, muitas das quais se mantêm intactas, tornando-se interessante atrativo turístico. A vida cultural da localidade tem por destaque a gastronomia baseada em frutos do mar, as festas religiosas da comunidade, como a Festa do Divino Espírito Santo - uma das tradições que a comunidade preserva até hoje, e no período do carnaval, o evento do Zé Pereira ou Carnaval Joga N’água.

\footnotetext{
*Mestre em História pela Universidade do Estado de Santa Catarina. Analista de Cultura da Secretaria de Estado do Turismo, Cultura e Esporte de Santa Catarina. Musicista, Instrutora de prática de instrumento e Coordenadora do setor de Memória, História e Patrimônio Cultural da Sociedade Musical e Recreativa Lapa. Email: lisandramacedo@hotmail.com
} 
O Zé Pereira é uma manifestação carnavalesca já conhecida com esse nome em Portugal, no século XIX, como manifestação musical popular executada através de instrumentos de percussão, encontradas, sobretudo, no norte de Portugal. Algumas pesquisas indicam que há influência lusitana nas manifestações similares encontradas em alguns lugares do Brasil, principalmente no Rio de Janeiro, Minas Gerais e Santa Catarina. Felipe Ferreira (2005, p. 209) aponta, porém, algumas divergências existentes na obra de alguns autores quanto à data de início dessas manifestações carnavalescas no Brasil, variando entre 1840 e 1952. Segundo o pesquisador, o fato é que em 1860 foram encontrados alguns periódicos que citavam a brincadeira do Zé Pereira como manifestação popular que ocorria no período carnavalesco.

Quanto ao personagem que inspirou o nome do folguedo, não há informações precisas. Como já foi citado, sabe-se que em Portugal já haviam manifestações intituladas como "Zé Pereira”, mas no Brasil, há um consenso entre alguns pesquisadores do carnaval brasileiro, quanto ao surgimento desta brincadeira. De acordo com estas pesquisas, o surgimento (ou a popularização) do Zé Pereira no Brasil teria ocorrido graças a um homem de origem portuguesa chamado José Nogueira, que, provavelmente com alguns companheiros, seguiu pelas ruas do Rio de Janeiro tocando instrumentos musicais percussivos como bumbos e caixas, entre o século XVIII e XIX. Felipe Ferreira (2005) aponta que as características do Zé Pereira, ainda no século XIX, não se davam necessariamente pelas vestimentas, características físicas, gênero ou poder aquisitivo, mas sim pelo tipo de som que era executado pelos instrumentos, uma "batida” característica, considerada por alguns críticos contemporâneos como "barulhenta e desordenada” (2005, p. 10). O pesquisador ainda salienta que “Zé Pereira” é uma denominação dada a diversas brincadeiras e folguedos, e que adquire, portanto, um caráter "generalizador", ao abarcar a multiplicidade de conceitos e manifestações culturais decorrentes.

Em Florianópolis, encontramos na imprensa, ao longo do século XX, algumas informações sobre o Zé Pereira, nas comunidades do centro da cidade. Conforme informou o jornal A Gazeta, em 16 de janeiro de 1935:

Ã tarde e ã noite do primeiro domingo de fevereiro, dia 3, vão ser do outro planeta, tal e tanta será a folia da gente séria desta terra. Naquelle dia, além do concurso de blocos e cordões, promovidos pelo pachà Feris Achid Mangala Boabaid, que já mandou buscar a taça a ser offerecida ao victorioso, também os Filhos de Minerva promoverão um ensurdecedor Zé Pereira, acompanhado por dois carros de critica(sic). 
No dia 4 de fevereiro do mesmo ano, outra manifestação carnavalesca do Zé Pereira foi noticiada no mesmo jornal:

Sahiu ôntem, á noite, á rua, o esperado Zé Pereira dos Tenentes do Diabo. Irrompendo de um dos cantos da Praça 15, o barulhento Zé Pereira surgiu garbosamente, ao toque de clarins, com suas interessantes allegorias.(sic)

Percebe-se, através das manchetes, que a manifestação do Zé Pereira em Florianópolis, já no século XX e, tal como classificam alguns críticos do carnaval carioca de décadas passadas, está sempre associada ao "barulho”, demonstrando que o grupo a se manifestar deve sempre vir acompanhado de instrumentos musicais e cânticos. O grupo torna-se, portanto, responsável pelo repertório musical do evento, chamando o grande público para as folias.

No Ribeirão da Ilha, no entanto, o Zé Pereira ocorre, desde os primeiros registros, semanas ou dias antes do Carnaval. Entre o final do século XIX e nas primeiras décadas do século XX, por falta de energia elétrica, as casas e as ruas do Ribeirão eram iluminadas com velas e lampiões, para que a banda do Zé Pereira pudesse passar. E ainda havia os desfiles dos carros alegóricos ou de mutação ${ }^{1}$, desaparecidos, segundo relatos, em 1932. Nos anos 50, com o crescimento da prática social do banho de mar, o Zé Pereira do Ribeirão da Ilha ganhou um diferencial: o banho à fantasia. Por tratar-se de um bairro que cresceu contornando a baía sul, as fantasias eram preparadas para se desmanchar na água, pois os participantes se lançavam ao mar ao final do desfile ${ }^{2}$.

Quanto ao repertório musical, de acordo com relatos de músicos e moradores participantes do evento ${ }^{3}$, não era diferente das manifestações musicais populares do período. Nas primeiras décadas do século XX, percebe-se a popularização dos sambas, das marchinhas e marchas-rancho, divulgadas por meio das apresentações de músicos e artistas conhecidos nacionalmente e, mais tarde, através da popularização da radiodifusão ${ }^{4}$. Quem executa as

\footnotetext{
${ }^{1}$ Os carros de mutação são carros alegóricos que possuem mecanismos para sua transformação ao longo dos desfiles carnavalescos, populares principalmente na primeira metade do século XX em Florianópolis. Neste período, os carros eram elaborados e exibidos pelas grandes sociedades carnavalescas, entidades existentes não só em Florianópolis como em outras cidades como Porto Alegre e Rio de Janeiro. A existência dos carros de mutação, porém só são registradas em Florianópolis, desde o século XIX. Para maiores informações, ver a dissertação de mestrado de Thaís Colaço, sobre o carnaval em Desterro no século XIX.

${ }^{2}$ Maiores informações sobre o Zé Pereira e outras manifestações culturais do Ribeirão da Ilha podem ser encontradas no livro "Ribeirão da Ilha: vidas e retratos, de Nereu do Vale Pereira e outros, e publicado em 1991.

${ }^{3}$ Informações obtidas través de conversas informais ocorridas ao longo de minha participação como musicista, atuando nos ensaios e eventos da Sociedade Musical e Recreativa Lapa.

${ }^{4}$ Em alguns jornais da década de 30, por exemplo, se encontram alguns indícios da popularidade do samba na cidade. No jornal O Estado, de 6 de maio de 1937 (capa), noticiava-se a morte do sambista Noel Rosa, enfocando sua contribuição para as manifestações carnavalescas em território nacional: “A' meia noite de ontem falleceu nesta capital [Rio de Janeiro], em sua residência (...) o compositor de sambas e marchas Noel Rosa. (...) De alguns annos pra cá, não havia Carnaval completo sem a música de Noel Rosa.” Em 1933, em várias edições publicadas durante o mês de fevereiro, o jornal O Estado publicou notas, divulgando um concurso de músicas
} 
músicas tocadas no Zé Pereira é a Banda Nossa Senhora da Lapa (hoje apenas Banda da Lapa). Fundada em 1896 e composta por músicos da comunidade, a Banda da Lapa, durante o ano, faz apresentações em eventos como as Festas do Divino, procissões, festivais e oficinas musicais. No carnaval, no entanto, a Banda da Lapa transforma-se na Banda do Zé Pereira, executando um repertório voltado para eventos carnavalescos.

Já os testemunhos, principalmente dos músicos mais antigos, como, por exemplo, o Sr. Arnoldo Feliciano, percussionista da Banda da Lapa há aproximadamente 52 anos, (observados e coletados por este pesquisador através de algumas conversas durante os ensaios), indicam que a banda sempre acompanhou os ritmos e as músicas evidentes em cada período de sua história: as marchas-rancho, os choros, os sambas e as marchinhas, sendo esses dois últimos os mais executados nos carnavais do país no século XX e, até hoje, são mantidos como símbolos do tradicional e típico carnaval brasileiro.

Nos últimos anos, notou-se evidente interesse por parte da mídia, e também pela população em geral, pela preservação deste tipo de manifestação cultural. Talvez a saturação dos novos ritmos e manifestações carnavalescas explique a tendência ao saudosismo e valorização das manifestações carnavalescas no século passado. Há quem não aprecie os blocos de axé-music de Salvador, com letras e danças que carregam forte apelo erótico, ou então os desfiles e os sambas-enredo das escolas de samba no sudeste e sul brasileiros, massificados pela padronização e profissionalização gerada pelo caráter competitivo do evento. Muitos acabam se voltando para o saudosismo das antigas marchas e sambas carnavalescos, defendendo o retorno ou a conservação desse tipo de evento ${ }^{5}$. É o caso do carnaval Zé Pereira do Ribeirão da Ilha. Eis aqui mais um exemplo do que foi chamado por alguns intelectuais de geração ou boom da memória.

Pode-se verificar, nas últimas décadas, o crescente interesse pela memória em busca da preservação do passado através dos vestígios presentes. A preocupação com a memória evidencia-se através das políticas culturais que se valem, muitas vezes, de eventos culturais, dos meios de comunicação e de outras manifestações político-culturais para se posicionar frente aos anseios da população cada vez mais descrente de um futuro promissor. Andreas Huyssen (2000) exemplifica essa questão quando cita o caso do Holocausto. Segundo ele, o

carnavalescas que valorizava as canções compostas por artistas catarinenses. A edição de 21.02.1933, por exemplo, noticiava a "Noite do samba" (p. 6), enfatizando a programação e as composições que, naquela noite, seriam apresentadas durante o concurso.

${ }^{5}$ Como musicista da Banda da Lapa, participei de algumas reuniões cuja pauta era a definição do repertório para o carnaval, ocorridas meses antes do período carnavalesco, nos anos de 2008 e 2009. Durante as reuniões, alguns músicos e regentes se manifestaram contra ou a favor da inclusão de novos gêneros musicais no repertório de carnaval da Banda da Lapa. 
Holocausto é a prova de que há um paradoxo na globalização da memória, pois assim como indica a incapacidade da civilização ocidental em lidar com as diferenças, também acaba se tornando um exemplo para se compreender outras experiências traumáticas paralelas e contemporâneas.

Assim como Huyssen, Beatriz Sarlo (2007) identifica o anseio pelas coisas do passado, à medida que a aceleração do tempo, nas últimas décadas, parece jogá-lo cada vez mais longe de nós. A chamada febre preservacionista provoca uma verdadeira caça às relíquias que pode tentar nos aproximar do passado como forma de não perder a identidade e as origens de cada pessoa, assim como de determinadas comunidades. E para Sarlo, a memória, por intermédio dos testemunhos, é peça fundamental para que haja a preservação e execução dos direitos que cada um tem à sua identidade, assim como também a preservação também da memória daqueles que não sobreviveram às experiências marcantes (e em sua maioria, trágicas) que constituem a história de determinado grupo social. Para Huyssen e Sarlo, as experiências, nesse caso as traumáticas, estão evidentes na memória do sujeito que fornece o testemunho ou da geração posterior que acompanha o processo de revitalização da memória através de eventos comemorativos, memoriais ou museus. Nesse caso, os testemunhos, os eventos, memoriais e monumentos são uma forma de lembrar e relegar aos antepassados o sofrimento e toda a experiência que levou a sociedade a se constituir e se estabelecer como está. E cabe à geração futura manter viva a lembrança, para que o futuro seja diferente do que foi no passado.

Certamente essas questões são importantes para pensarmos como tem se estabelecido, ao longo desses anos, as políticas da memória e da preservação, que acabam se colocando à frente das manifestações culturais de diferentes comunidades ou grupos sociais. Porém, diferentemente do que colocam os pesquisadores citados, percebemos que no caso das manifestações culturais que procuram preservar a tradição como o carnaval, por exemplo, o discurso se inverte.

No caso do Holocausto ou dos testemunhos dos torturados durante as Ditaduras da América Latina (estudados por Sarlo), as experiências traumáticas do passado se colocam em evidência e impelem o sujeito a evidenciar as experiências (negativas), mas, sobretudo valorizando seu tempo presente e o futuro que pode ser construído de forma diferente (pois é um sobrevivente). No entanto, ao tomar, por exemplo, os carnavais brasileiros, há uma tendência entre os indivíduos que participaram de forma ativa ou indireta nas manifestações culturais de outras décadas, a valorizar os antigos eventos e tudo que estiver ligado a ele (as músicas, o ambiente e o caráter das pessoas envolvidas). Sendo assim, refuta qualquer 
inovação ou descaracterização destes eventos culturais manifestados pelas novas gerações. Há, portanto, uma inversão de valores. No primeiro caso, o passado sofrido e ruim é lembrado ou exaltado para que a nova geração valorize seu presente (menos conflituoso, talvez) e principalmente possa se comportar ou se posicionar de forma diferente no futuro, sem esquecer, contudo, suas raízes e aqueles que lutaram contra um determinado sistema, visando a interesses individuais ou político-culturais. No segundo caso, o passado é valorizado e tido como bem melhor que o presente; portanto, as próximas gerações devem manter conservados os eventos, as manifestações culturais e o comportamento que é motivo de orgulho e sensação de pertencimento a determinado grupo social. Em ambos, portanto, percebe-se que a questão da identidade cultural e as incertezas quanto ao futuro são questões que impulsionam a geração contemporânea a valorizar a memória e a patrimonialização de sujeitos, objetos e manifestações culturais.

Nas manifestações carnavalescas não faltam motivos explicitados pelos grupos sociais, de forma a manter ou estabelecer o retorno de certos eventos esquecidos em décadas anteriores. Muito devem, por exemplo, aos altos índices de violência ou erotismo explícito que costumam ser freqüentes nessas ocasiões. Não que as transgressões ocorridas no carnaval sejam coisa recente. O Entrudo, o Zé Pereira, e tantas outras manifestações carnavalescas já eram noticiados como atos subversivos, nos séculos anteriores ${ }^{6}$. O próprio uso da fantasia no período de momo já denota a inversão da realidade, conforme aponta Claudia Matos (1982). O indivíduo fantasiado se posiciona contra as censuras e a hierarquia imposta pela sociedade durante o ano. É uma forma de criticar ou protestar contra alguma situação que o incomoda. É ainda uma forma de satisfazer seus desejos, criando coragem ou condições para fazê-lo. Ao se esconder por detrás de uma fantasia, as pessoas “podem” ser ou fazer o que desejarem.

Aprofundando esta discussão, voltamos às manifestações do Carnaval Zé Pereira do Ribeirão da Ilha. Nos últimos anos, é notório o aumento no número dos participantes no evento, assim como a cobertura da mídia. Em 2008, o site Floripa Anúncios noticiou o evento da seguinte forma:

Ribeirão da Ilha resgata folia do Zé Pereira. Carnavalescos do bairro homenageiam a tradicional Banda Nossa Senhora da Lapa.

"E viva o Zé Pereira, pois a ninguém faz mal; e viva a bebedeira nos dias de Carnaval..." Cantado na encenação de uma comédia chamada "O Zé Pereira Carnavalesco", em 1870, no Rio de Janeiro, o refrão se tornou quase um hino de Carnaval e se espalhou pelo País com a mesma rapidez que a

\footnotetext{
${ }^{6}$ Essas informações foram extraídas a partir da leitura da publicação de Alexandre Lazzari (2001), fruto de sua Dissertação de Mestrado, intitulada Coisas para o povo não fazer: Carnaval em Porto Alegre (1870 - 1915).
} 
brincadeira do famoso personagem. Essência da festa de Momo no Ribeirão da Ilha, o Carnaval do Zé Pereira é motivo da reorganização dos blocos e resgate dos antigos valores carnavalescos do bairro. O desfile do último domingo, mais que o encontro dos blocos organizados (Rua de Cima, Apito do Agenor e Bloco do ET), foi uma justa homenagem à banda Nossa Senhora da Lapa, uma das principais atrações da folia há 111 anos. $^{7}$

Até mesmo na divulgação do evento, percebemos como está embutida a valorização dos antigos carnavais através da escolha do repertório musical. No site da Banda da Lapa, por exemplos, encontramos o seguinte texto de divulgação, referindo-se ao evento que ocorreria em 2010:

O dia 07 de fevereiro está marcado para se jogar na água e curtir o tradicional Zé Pereira. O resgate do passado nas inesquecíveis marchinhas fica por conta da Banda do Zé Pereira, que há mais de 60 carnavais anima milhares de moradores e turistas nas ruas do Ribeirão da Ilha. A alegria é embalada por mais de 20 músicos divididos em vocais, flautins, saxofones, trompetes, trombones, bateria, percussão, cavaco, baixo e guitarra elétrica. A Banda faz parte da Sociedade Musical e Recreativa Lapa, fundada há 113 anos, e organizadora do carnaval do Zé Pereira. O Joga n’água, como também é conhecido, será no próximo domingo, a partir das 15 horas, na Freguesia do Ribeirão da Ilha, e como de costume, uma semana antes do carnaval para noticiar a folia. ${ }^{8}$

Percebemos através das frases "resgate dos antigos valores carnavalescos" e "resgate do passado” a forma de atualização do evento como forma de se buscar a identidade cultural da região. Assim, para os músicos e para a comunidade em geral, é importante conservar o repertório, salientando que as “inesquecíveis marchinhas” serão executadas.

Henri-Pierre Jeudy (2005) salienta que o ato de atualizar aquilo que não está mais no presente, ao estabelecer uma atemporalidade e um poder de contemporaneidade acaba por desestabilizar as representações do tempo presente. ${ }^{9}$ A execução dos ritmos dos antigos carnavais será o elo, ou talvez, utilizando a expressão difundida por Pierre Nora (1984), o lugar de memória, o objeto que vai sempre conferir atemporalidade ao evento. Logo, a inclusão de qualquer outro ritmo de criação mais recente no repertório, ou até mesmo alteração no andamento ou na melodia das marchas e sambas tradicionais já alterariam e desvinculariam o atual Zé Pereira daqueles que eram manifestados há décadas atrás. ${ }^{10}$ Nesse

\footnotetext{
${ }^{7}<$ http://www.floripanuncios.com/noticias_ver.php?COD_NOTICIA=27>. Acesso em: 27 jan. 2010.

${ }^{8}<$ http://www.bandadalapa.com.br>. Acesso em: $1^{\circ}$ fev. 2010.

${ }^{9}$ JEUDY. Henry-Pierre Jeudi. A Maquinaria Patrimonial In 2005. p 51.

${ }^{10}$ Estas observações foram feitas a partir da convivência pessoal com músicos e a comunidade da Banda da Lapa, nos quatro últimos anos. Há um embate entre os músicos mais antigos com os mais novos, no que se refere
} 
sentido, há um paradoxo que nos faz refletir até que ponto a reconstituição do evento, a organização e a manifestação cultural previamente estabelecida se torna algo realmente produtivo para mantermos uma identificação cultural no presente, e até onde essa espécie de culto coletivo ao passado pode ter efeito contrário e descaracterizar toda uma geração que não vive para o seu tempo, rejeitando e julgando manifestações culturais recentes, por (falta de) qualificação ou por saudosismo.

Ora, se nos primórdios de sua manifestação, o carnaval Zé Pereira tinha como repertório, canções e manifestações culturais de seu tempo, inclusive canções originárias de outros locais e outros grupos carnavalescos ${ }^{11}$, e se manteve assim por algumas décadas, isso significa que a característica do evento é manter-se conectado com as tendências musicais contemporâneas. Sendo assim, para os mais conservadores, não haveria problemas na alteração do repertório, à medida que novas canções populares passassem a fazer sucesso entre o grande público. Mas, como entender, então, a opção repentina por conservar as canções dos antigos repertórios, que acabou por se tornar mais importante para a os valores da tradição e objeto de identificação cultural?

Já vimos que a valorização da memória é uma tendência mundial e tema de muitas discussões entre intelectuais da contemporaneidade, como os já citados Andreas Huyssen e Beatriz Sarlo, e também Jay Winter. A preocupação emergente com a memória, ou nas palavras de Winter (2006), o boom da memória, nasce de uma série de fatores sociais, que se entrecruzam e, dentro de sua lógica, impulsionam a busca obsessiva pelo passado. A aceleração do tempo, os grandes saltos tecnológicos parecem nos empurrar para cada vez mais longe das origens, de um berço, de laços que nos identificam e nos caracterizam enquanto indivíduos inseridos num contexto social.

Mas, ao mesmo tempo em que a inovações tecnológicas nos distanciam dos antepassados, pelos atos cotidianos, essa mesma tecnologia nos permite "virtualizar" a memória, e, de certa forma, atualizá-la, imortalizá-la, através de gravadores, filmadoras e fotografias de crescente qualidade. O acesso a esses dados permite nos conectarmos ao passado, e trazê-lo sempre ao presente. Tem sido cada vez mais fácil "reproduzir” o passado. Dessa forma, a presentificação do passado leva à patrimonialização do mesmo. Quando se identifica algo como tradicional, inserem-se, nele, valores que permitem às gerações futuras o

\footnotetext{
à escolha do repertório, a cada ano. Estes últimos são a favor da inclusão de ritmos como axé music e pagode, ou alterações na execução das marchas e sambas. Já os músicos mais antigos ou que defendem a preservação dos ritmos tal como eram executados, defendem a conservação dos antigos repertórios.

${ }^{11}$ Um exemplo para esta informação é a música "Oba (Bafo da Onça)" (autoria desconhecida), composta na década de 60 para o Bloco Carnavalesco Bafo da Onça, situado no Rio de Janeiro.
} 
reconhecimento de seu lugar de formação, suas raízes. Para isso, o objeto em questão se torna patrimônio. Por isso a reconstituição permitida pela tecnologia, pelos lugares de memória e pela oficialização do patrimônio (através dos tombamentos e registros em seus respectivos livros) mantém viva a memória daqueles que já não são nossos contemporâneos. A tecnologia também atinge a mídia. E esta, por sua vez, mantém a tendência à valorização da memória e do culto ao passado, divulgando-os como forma a lembrar sempre que há algo que se conservar e valorizar. Isto está implícito em novelas de época, em séries biográficas, em divulgação de eventos de cunho tradicional ou secular.

A celebração de eventos que se repetem, permitem sempre essa conexão com o passado, através dos elementos que os simbolizam. O carnaval, nesse sentido, sempre representou o momento de descanso, ou de transgressões a regras ou afazeres que normalmente não são permitidos ao longo do ano. Nesse período, a única regra permitida é o direito à diversão e ao lazer. Também é permitido manifestar-se contra algo de que se discorda. Situações sociais, políticas ou familiares são motivos para a sátira ou protesto estampado nas fantasias ou nas canções carnavalescas. Isso por si só já valoriza o carnaval como manifestação tradicional e até mesmo essencial às necessidades humanas. Ao escapar dos afazeres cotidianos, o ser humano se reinventa nas artes de fazer (se apropriando do termo de Michel de Certeau) e de se reinventar, como estratégia de sobrevivência e permanência em sociedade.

Embalando essas situações de escapismo e resistência, estão as canções populares. Levando em consideração as observações de Marcos Napolitano (2007), que eleva a música popular a objeto de memória coletiva, percebemos, então, que as canções carnavalescas simbolizam e traduzem o estado de espírito de seus foliões. São melodias de andamento acelerado, letras alegres carregadas de duplo sentido, euforia, alegria ou sátiras a tipos físicos ou a situações políticas, econômicas ou comportamentais.

Ao entrar em contato com essas canções, o indivíduo se permite reviver ou compreender como viviam seus antepassados em situações como o carnaval. O sentimento de pertencimento a algum lugar, despertado na memória que é ativada pelas melodias e acordes, coloca-o em sintonia com um momento que é atemporal: é o passado atualizado e reinventado nas canções eternizadas, muitas das quais trazem questões e situações típicas do momento em que foram criadas. Para a geração posterior que as ouve, não importa. Basta ouvi-las para que seja despertada nelas o sentimento que o momento do carnaval propõe: lazer, alegria, transgressão à ordem e a alguns valores massificados pela ordem vigente. Seguindo as canções, eles vão em frente abrindo alas, transformando-se em reis, chiquitas bacanas, piratas 
da perna de pau ou pierrôs apaixonados - esses sujeitos vão lançando, nas páginas do tempo presente, histórias que se entrecruzam e lhes permitem fazer jus ao título de geração da memória.

\title{
TRADITION X INNOVATION: memory and cultural heritage through musical repertoires in Zé Pereira Carnival in Florianópolis/SC
}

\begin{abstract}
This paper seeks to identify the movements of joints and preservation of cultural identity on the island of Santa Catarina, which occurs implicitly in the revitalization of events such as Carnival Zé Pereira, who for more than one hundred years occurs in the vicinity of Ribeirão da Ilha district, in Florianópolis / SC, which in recent years has been highlighted in planning the carnival events in Santa Catarina, both in the media, as the increase in the number of participants. The choice of musical repertoire, from the leaders of the Musical Society and Recreation Lapa, which promotes the event, and the manifestations of the communities involved and the media in relation to the rhythms performed, generate discussions that can enrich the very issues that involve the preservation cultural events involving the town, listed by the local historical heritage.
\end{abstract}

Keywords: Intangible Heritage. History. Musical Memory.

\section{Referências}

A Gazeta. Florianópolis, 16 de janeiro de 1935. P. 4.

A Gazeta. Florianópolis, 4 de fevereiro d e 1935. P. 4.

COLAÇO, Thais Luzia. O carnaval do desterro: século XIX. CFH/UFSC, 1988 (Dissertação de mestrado).

FERREIRA, Felipe. O livro de ouro do carnaval brasileiro. Rio de Janeiro: Ediouro, 2005. P. 209.

Floripa Anúncios. Disponível em:

<http://www.floripanuncios.com/noticias_ver.php?COD_NOTICIA=27>. Acesso em: 27 jan. 2010.

HUYSSEN, Andreas. Passados presentes: mídia, política, amnésia. In: Seduzidos pela memória. RJ: Aeroplano, Universidade Cândido Mendes, Museu de Arte Moderna do Rio de Janeiro, 2000. P. 9-40.

JEYDY, Henri-Pierre. A maquinaria patrimonial. In: Espelho das cidades. RJ: Casa da

Palavra, 2005. P 15-78. 
LAZZARI, Alexandre. Coisas para o povo não fazer: Carnaval em Porto Alegre (1870 1915). Campinas/SP: Editora da Unicamp/Cecult, 2001.

MATOS, Cláudia Neiva de. Acertei no milhar: samba e malandragem no tempo de Getúlio. RJ: Paz e Terra, 1982.

NAPOLITANO, Marcos. A Síncope das Idéias. SP: Perseu Abramo, 2007.

NORA, Pierre. Entre memória e história: a problemática dos lugares. Projeto História, SP, $\mathrm{n}^{\mathrm{0}}$ 10, p.7-28, dez. 1993.

O Estado. Florianópolis, 6 de maio de 1937. Capa.

O Estado. Florianópolis, 20 de fevereiro de 1933. P. 6.

O Estado. Florianópolis, 21 de fevereiro de 1933. P. 6.

O Estado. Florianópolis, 22 de fevereiro de 1933. P. 6.

PEREIRA, N. V.; PEREIRA, F. V.; SILVA NETO, W. J, Ribeirão da Ilha: vida e retratos. Florianópolis: Fundação Franklin Cascaes, 1991.

SARLO, Beatriz. Tempo Passado. SP: Cia das Letras; Belo Horizonte: Editora UFMG, 2007. Sociedade Musical e Recreativa Lapa. <http://www.bandadalapa.com.br>. Acesso em: $1^{\mathrm{o}} \mathrm{fev}$. 2010.

WINTER, Jay. A geração da memória: reflexões sobre o boom da memória nos estudos contemporâneos de história. In: SELLIGMANN-SILVA, Márcio (org.). Palavra e Imagem, Memória e escritura. Chapecó (SC): Argos, 2006, p. 67-90. 